\title{
SISTEM PENILAIAN KINERJA JURUSAN/ PROGRAM STUDI DI PERGURUAN TINGGI MENGGUNAKAN DATA ENVELOPMENT ANALYSIS (DEA)
}

\author{
Denny Hernadinata Nugraha , Beta Noranita \\ Jurusan Ilmu Komputer / Informatika Universitas Diponegoro \\ denny.hn@,outlook.com, betta@undip.ac.id
}

\begin{abstract}
Abstrak
Penilaian kinerja jurusan merupakan kegiatan rutin yang dilakukan universitas untuk terus meningkatkan kualitas layanannya. Salah satu bentuk penilaian kinerja jurusan/ program studi adalah akreditasi institusi tersebut. Oleh karena itu, perlu dibangun suatu sistem yang mampu melakukan penilaian kinerja jurusan secara otomatis. Dalam penilaian kinerja sering dijumpai variable-variabel yang digunakan bersifat kuantitatif dan/atau kualitatif. Data Envelopment Analysis (DEA) dapat dipandang sebagai operator agregasi untuk variable yang bernilai kuantitatif dan kualitatif. Sistem penilaian kinerja jurusan ini menggunakan metode Data Envelopment Analysis (DEA) dan metode pengembangan perangkat lunak yang digunakan yaitu Waterfall. Sistem ini menghasilkan suatu nilai efisiensi tingkat kinerja jurusan apakah sudah optimal atau belum, jika belum maka sistem ini akan memberikan bahan pertimbangan nilai variabel/ atribut mana yang perlu dikurangi atau ditambah.
\end{abstract}

Kata Kunci : Data Envelopment Analysis (DEA), sistem penilaian kinerja jurusan, universitas

\section{PENDAHULUAN}

Undang-Undang Dasar 1945 mengamanatkan Pemerintah untuk menyelenggarakan satu sistem pendidikan nasional yang diatur dengan undangundang, yang meliputi Undang-Undang No.2 / 1989 tentang Sistem Pendidikan Nasional, Undang-Undang No.20 / 2003, dan UndangUndang No.12 / 2012 tentang Pendidikan Tinggi. BAN-PT merupakan lembaga nonstruktural di bawah Menteri Pendidikan dan Kebudayaan yang pada hakekatnya melambangkan niat dan kepedulian pemerintah dalam pembinaan penyelenggaraan perguruan tinggi, melayani kepentingan masyarakat, dan kemajuan ilmu pengetahuan teknologi untuk meningkatkan taraf kehidupan masyarakat dan memperkaya kebudayaan nasional.

Salah satu bentuk penilaian kinerja jurusan / program studi adalah akreditasi institusi tersebut. Dalam penilaian akreditasi terdapat tujuh komponen yang dinilai, yang meliputi : visi dan misi, kepemimpinan dan tata kelola, mahasiswa dan lulusan, sumber daya manusia, kurikulum dan implementasinya, dana dan sarana, dan penelitian dan pengabdian serta kerjasama antar lembaga [2]. Pada umumnya, peningkatan kualitas jurusan / program studi berhubungan secara linear dengan efisiensi dan produktivitasnya.

Dalam penilaian kinerja, sering dijumpai variabel-variabel yang digunakan bersifat kuantitatif dan/atau kualitatif. Diperlukan suatu operator agregasi yang dapat didefinisikan pada variabel-variabel tersebut. Data Envelopment Analysis (DEA) dapat dipandang sebagai operator agregasi untuk variable yang bernilai kuantitatif dan kualitatif [4].

Penilaian kinerja jurusan merupakan kegiatan rutin yang dilakukan universitas untuk terus meningkatkan kualitas layanannya. Oleh karena itu, perlu dibangun suatu sistem yang mampu melakukan penilaian kinerja jurusan secara otomatis.

\section{Ruang Lingkup}

Ruang lingkup pada sistem penilaian kinerja jurusan / program studi di PT menggunakan Data Envelopment Analysis (DEA) adalah sebagai berikut:

1. Sistem akan diimplementasikan berbasis web yaitu menggunakan bahasa pemrograman PHP dan DBMS menggunakan MySQL

2. Sistem melakukan proses perhitungan efisiensi jurusan dan penentuan variabel apa 
saja yang perlu dinaikan atau diturunkan nilainya

3. Sistem memiliki 2 (dua) jenis use

4. Penghitungan nilai efisiensi menggunakan formula CRS (constant returns to scale) input-oriented

\section{TINJAUAN PUSTAKA}

\section{Definisi Sistem Pendukung Keputusan (SPK)}

Menurut Turban sistem pendukung keputusan merupakan suatu pendekatan (atau metodologi) untuk mendukung pengambilan keputusan. Sistem pendukung keputusan sebaiknya fleksibel, interaktif dan dapat diadaptasi untuk mendukung solusi suatu masalah manajemen spesifik yang tidak terstruktur. Sebagai tambahan, sistem pendukung keputusan biasanya menggunakan berbagai model dan dibangun melalui suatu proses interaktif dan iteratif. Sistem dapat digunakan oleh pengguna tunggal pada satu PC atau bisa menjadi berbasis web untuk digunakan oleh banyak orang pada beberapa lokasi [10].

\section{Metode Data Envelopment Analysis (DEA)}

Data envelopment analisis merupakan metode non-parametrik yang menggunakan program linear sebagai pendekatan matematisnya. DEA adalah suatu teknik pemrograman matematika yang mengukur tingkat efisiensi dari unit pengambil keputusan (UPK) atau decisionmaking unit (DMU) relatif terhadap DMU yang sejenis ketika semua unit-unit ini berada pada atau dibawah "kurva" efisien frontiernya [3]. Model DEA dapat dibangun melalui dua pendekatan, yakni berorientasi input dan berorientasi output. DEA berorientasi input adalah model DEA yang meminimalkan input dengan mengasumsikan outputnya konstan. Sebaliknya, DEA berorientasi output adalah model DEA yang memaksimalkan output dengan mengasumsikan inputnya konstan [11].

Langkah kerja penyelesaian dengan metode DEA ini meliputi :

1. identifikasi dmu atau unit yang akan diobservasi.

2. identifikasi input dan output pembentuk dmu.
3. menghitung efisiensi tiap dmu. Tujuannya yaitu mendapatkan target input dan output yang diperlukan untuk mencapai kinerja optimal. Cara melakukan proses hitung efisiensi ialah dengan menjabarkannya ke dalam bentuk matematis (program linear), kemudian dalam menyelesainkan program linear tersebut digunakan metode simpleks.

Rumus CRS input-oriented sebagai berikut [3] : Tabel 1. Rumus CRS

\begin{tabular}{l}
\hline \multicolumn{2}{c}{ Input-Oriented } \\
\hline $\min \theta-\varepsilon\left(\sum_{i=1}^{m} s_{i}^{-}+\sum_{r=1}^{s} s_{r}^{+}\right)$ \\
Subject to: \\
$\sum_{j=1}^{n} \lambda_{j} x_{i j}+s_{i}^{-}=\theta x_{i o} \quad, \mathrm{i}=1,2, \ldots, \mathrm{m} ;$ \\
$\sum_{j=1}^{n} \lambda_{j} y_{r j}-s_{i}^{+}=y_{r o} \quad, r=1,2, \ldots, s ;$ \\
$\lambda_{j} \geq 0 \quad, j=1,2, \ldots, n$. \\
\hline
\end{tabular}

Keterangan:

$\theta=$ nilai efisiensi

$\varepsilon=$ angka positif yang kecil

$\mathrm{S}_{\mathrm{i}}=$ slack ke-i

$\lambda_{\mathrm{j}}=$ bobot DMU ke-j

$\mathrm{X}_{\mathrm{ij}}=$ nilai input ke-ij

$Y_{\mathrm{rj}}=$ nilai output ke-rj

$\mathrm{i}=$ jumlah input

$\mathrm{r}=$ jumlah output

$\mathrm{j}=$ jumlah DMU

\section{PEMBAHASAN}

\section{Aristektur Sistem}

Aristektur sistem penilaian kinerja jurusan dapat dilihat pada Gambar 1.

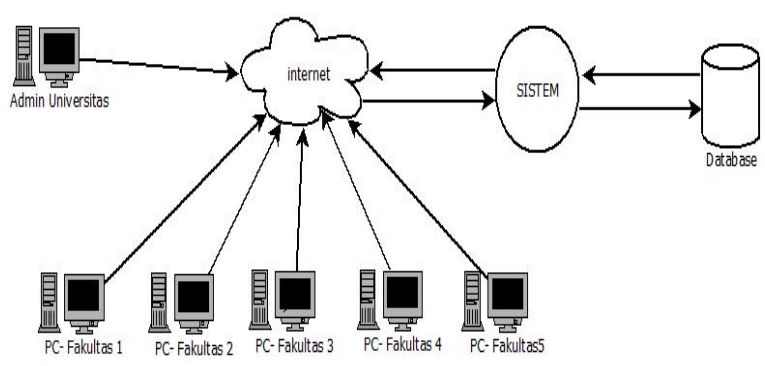

Gambar 1. Arsitektur Sistem Penilaian Kinerja Jurusan 


\section{Penerapan DEA pada Sistem Penilaian Kinerja Jurusan/ Program Studi}

Pada kasus ini ada dua variabel input, tiga variabel output, dan tiga dmu. Dmu yang digunakan ialah jurusan. Variabel input1 adalah jumlah dosen (orang) dan input2 adalah alokasi dana riset (juta rupiah). Variabel output1 adalah jumlah artikel yang dipresentasikan dalam seminar (buah), output2 adalah jumlah artikel yang ditulis dalam jurnal (buah), dan output3 adalah jumlah penelitian yang didanai (buah).

Masukan detail dmu

Tabel 2 Contoh kasus

\begin{tabular}{llllll}
\hline DMU & Input1 & Input2 & Output1 & Output2 & Output3 \\
\hline $\mathbf{1}$ & 5 & 14 & 9 & 4 & 16 \\
$\mathbf{2}$ & 8 & 15 & 5 & 7 & 10 \\
$\mathbf{3}$ & 7 & 12 & 4 & 9 & 13 \\
\hline
\end{tabular}

Perhitungan akan dilakukan pada dmu ke-2.

Tabel 3 Iterasi 0

\begin{tabular}{llllcccc}
\hline Basis & $\mathbf{X 1}$ & $\mathbf{X 2}$ & $\mathbf{X 3}$ & $\mathbf{X 4}$ & $\mathbf{X 5}$ & $\mathbf{X 6}$ & Solusi \\
\hline $\mathbf{Z}$ & $-(19 / 23)$ & -1 & - & 0 & 0 & 0 & 0 \\
$\mathbf{X}_{\mathbf{4}}$ & -9 & -5 & -4 & 1 & 0 & 0 & -5 \\
$\mathbf{X}_{\mathbf{5}}$ & -4 & -7 & -9 & 0 & 1 & 0 & -7 \\
$\mathbf{X}_{\mathbf{6}}$ & -16 & -10 & -13 & 0 & 0 & 1 & -10 \\
\hline
\end{tabular}

Tabel 4 Iterasi 1

\begin{tabular}{llllllll}
\hline Basis & $\mathbf{X}_{\mathbf{1}}$ & $\mathbf{X}_{\mathbf{2}}$ & $\mathbf{X}_{\mathbf{3}}$ & $\mathbf{X}_{\mathbf{4}}$ & $\mathbf{X}_{\mathbf{5}}$ & $\mathbf{X}_{\mathbf{6}}$ & Solusi \\
\hline $\mathbf{Z}$ & 0 & - & -0.154 & 0 & 0 & - & 0.5163 \\
& & 0.483 & & & & 0.051 & \\
$\mathbf{X}_{\mathbf{4}}$ & 0 & 0.625 & 3.3125 & 1 & 0 & - & 0.625 \\
& & & & & & 0.562 & \\
$\mathbf{X}_{\mathbf{5}}$ & 0 & -4.5 & -5.75 & 0 & 1 & -0.25 & -4.5 \\
$\mathbf{X}_{\mathbf{1}}$ & 1 & 0.625 & 0.8125 & 0 & 0 & - & 0.625 \\
& & & & & & 0.062 & \\
\hline
\end{tabular}

Tabel 5 Iterasi 2

\begin{tabular}{llllllll}
\hline Basis & $\begin{array}{l}\mathbf{X} \\
\mathbf{1}\end{array}$ & $\mathbf{X}_{\mathbf{2}}$ & $\mathbf{X}_{\mathbf{3}}$ & $\mathbf{X}_{\mathbf{4}}$ & $\mathbf{X}_{\mathbf{5}}$ & $\mathbf{X}_{\mathbf{6}}$ & Solusi \\
\hline $\mathbf{Z}$ & 0 & -0.362 & 0 & 0 & -0.026 & -0.049 & - \\
& & & & & & & 0.6375 \\
$\mathbf{X}_{\mathbf{4}}$ & 0 & -1.967 & 0 & 1 & 0.576 & -0.706 & - \\
& & & & & & & 1.9674 \\
$\mathbf{X}_{\mathbf{3}}$ & 0 & 0.7826 & 1 & 0 & -0.173 & 0.0435 & 0.7826 \\
$\mathbf{X}_{\mathbf{1}}$ & 1 & -0.010 & 0 & 0 & 0.1413 & -0.097 & - \\
& & & & & & & 0.0109 \\
\hline
\end{tabular}

Tabel 6 Iterasi 3 (Iterasi Optimal)

\begin{tabular}{llllllll}
\hline Basis & $\mathbf{X}_{\mathbf{1}}$ & $\mathbf{X}_{\mathbf{2}}$ & $\mathbf{X}_{\mathbf{3}}$ & $\mathbf{X}_{\mathbf{4}}$ & $\mathbf{X}_{\mathbf{5}}$ & $\mathbf{X}_{\mathbf{6}}$ & Solusi \\
\hline $\mathbf{Z}$ & 0 & -0.237 & 0 & -0.063 & -0.063 & 0 & 0.7625 \\
$\mathbf{X}_{\mathbf{6}}$ & 0 & 2.7843 & 0 & -1.415 & -0.815 & 1 & 2.7843 \\
$\mathbf{X}_{\mathbf{3}}$ & 0 & 0.6615 & 1 & 0.0616 & -0.138 & 0 & 0.6615 \\
$\mathbf{X}_{\mathbf{1}}$ & 1 & 0.2614 & 0 & -0.138 & 0.0616 & 0 & 0.2614 \\
\hline
\end{tabular}

Hasil $Z=0.7625$ (nilai efisiensi), $X_{1}=0.2614$, $\mathrm{X}_{2}=0$, dan $\mathrm{X}_{3}=0.6615$.

Parameter input :

$$
0.2614\left[\begin{array}{c}
5 \\
14
\end{array}\right]+0.6615\left[\begin{array}{c}
7 \\
12
\end{array}\right]=\left[\begin{array}{c}
5.938 \\
11.598
\end{array}\right]
$$

Parameter output :

$$
0.2614\left[\begin{array}{c}
9 \\
4 \\
16
\end{array}\right]+0.6615\left[\begin{array}{c}
4 \\
9 \\
13
\end{array}\right]=\left[\begin{array}{c}
5 \\
7 \\
12.78
\end{array}\right]
$$

Hasil rekomendasi/evaluasi untuk jurusan ke2 adalah adanya penurunan nilai pada parameter input, kenaikan pada parameter ouput3, dan pada parameter output 1 output2 nilai tetap sama. Pengurangan jumlah dosen dari 8 orang menjadi 6 orang (pembulatan dari 5,938 orang), pengurangan alokasi dana jurusan untuk penelitian dari $\mathrm{Rp} 15.000 .000,00$ menjadi $\mathrm{Rp}$ 12.000.000,00 (pembulatan dari 11,598 juta rupiah), jumlah artikel yang dipresentasikan dalam seminar tetap 5 buah, jumlah artikel yang ditulis dalam jurnal tetap 7 buah, dan penambahan jumlah penelitian dari 10 buah menjadi 13 buah (pembulatan dari 12,78 buah)

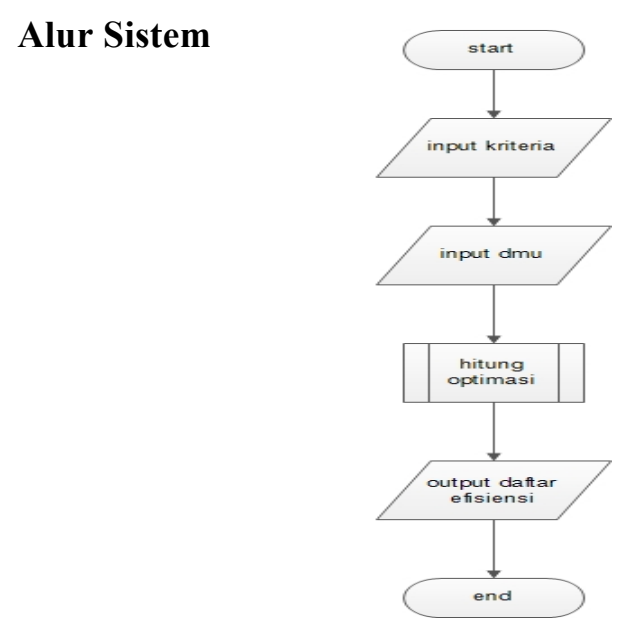

Gambar 2. Flowcahart Sistem Penilaian Kinerja Jurusan 
Awal masuk sistem ialah pada halaman menu utama. Kemudian sistem melakukan input kriteria. Setelah itu sistem melakukan input dmu. Lalu sistem akan menjalankan proses hitung optimasi. Dan pada akhirnya sistem menghasilkan daftar efisiensi.

\section{Implementasi Antarmuka}

Tampilan halaman utama dan halaman hasil sistem penilaian kinerja jurusan dapat dilihat pada gambar 3 dan gambar 4 .

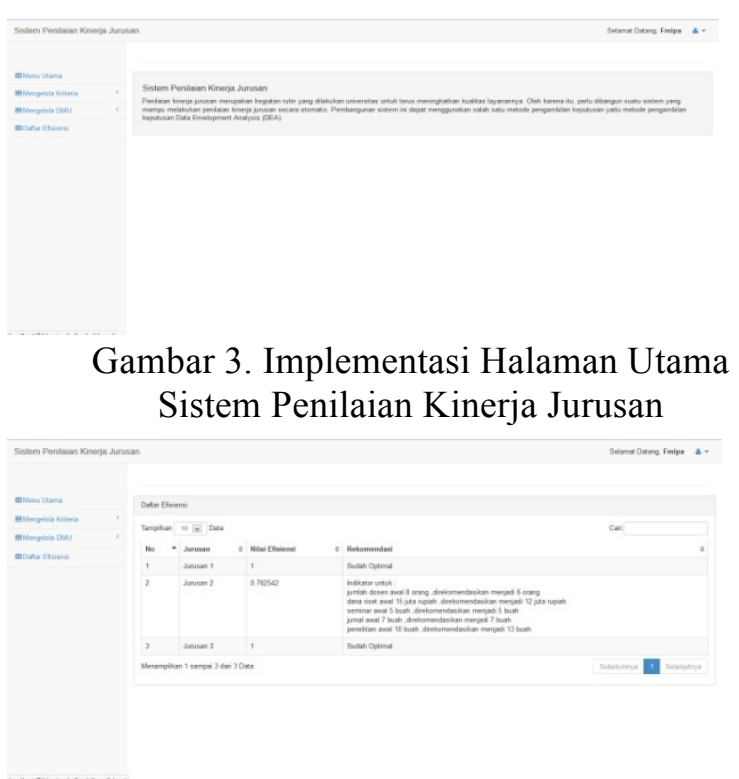

Gambar 4. Implementasi Halaman Hasil Sistem Penilaian Kinerja Jurusan

\section{PENGUJian}

Pengujian yang dilakukan secara black box yaitu pengujian dilakukan dengan memperhatikan masukan ke sistem dan keluaran daris sistem. hasil pengujian sistem dapat dilihat pada tabel 7 .

Tabel 7. Hasil Pengujian

\begin{tabular}{|c|c|c|}
\hline Kelas Uji & Butir Uji & Kesimpulan \\
\hline \multirow{2}{*}{$\begin{array}{l}\text { Menambah } \\
\text { kriteria }\end{array}$} & $\begin{array}{l}\text { menginputkan } \\
\text { data kriteria } \\
\text { dengan benar }\end{array}$ & Diterima \\
\hline & $\begin{array}{l}\text { tidak mengisi } \\
\text { salah satu data }\end{array}$ & Diterima \\
\hline $\begin{array}{l}\text { Menambah } \\
\text { detail dmu }\end{array}$ & $\begin{array}{l}\text { menginputkan } \\
\text { data kriteria } \\
\text { dengan benar }\end{array}$ & Diterima \\
\hline
\end{tabular}

\begin{tabular}{|c|c|c|}
\hline Kelas Uji & Butir Uji & Kesimpulan \\
\hline & $\begin{array}{l}\text { tidak mengisi } \\
\text { salah satu data }\end{array}$ & Diterima \\
\hline $\begin{array}{l}\text { Menghapus } \\
\text { kriteria }\end{array}$ & $\begin{array}{l}\text { penghapusan } \\
\text { data kriteria } \\
\text { berdasarkan id } \\
\text { kriteria }\end{array}$ & Diterima \\
\hline $\begin{array}{l}\text { Menghapus } \\
\text { detail dmu }\end{array}$ & $\begin{array}{l}\text { penghapusan } \\
\text { data detail dmu } \\
\text { berdasarkan id } \\
\text { dmu }\end{array}$ & Diterima \\
\hline $\begin{array}{l}\text { Mengubah } \\
\text { kriteria }\end{array}$ & $\begin{array}{l}\text { mengubah data } \\
\text { kriteria dengan } \\
\text { benar }\end{array}$ & Diterima \\
\hline $\begin{array}{l}\text { Mengubah } \\
\text { detail dmu }\end{array}$ & $\begin{array}{l}\text { Mengubah data } \\
\text { detail dmu } \\
\text { dengan benar }\end{array}$ & Diterima \\
\hline $\begin{array}{l}\text { Mengubah } \\
\text { profil user }\end{array}$ & $\begin{array}{l}\text { Mengubah data } \\
\text { detail dmu } \\
\text { dengan benar }\end{array}$ & Diterima \\
\hline $\begin{array}{l}\text { Menghitung } \\
\text { optimasi }\end{array}$ & $\begin{array}{l}\text { melakukan } \\
\text { proses hitung } \\
\text { optimasi dan } \\
\text { menyimpan pada } \\
\text { database } \\
\end{array}$ & Diterima \\
\hline $\begin{array}{l}\text { Menampilkan } \\
\text { hasil daftar } \\
\text { efisiensi }\end{array}$ & $\begin{array}{l}\text { menampilkan } \\
\text { daftar efisiensi } \\
\text { hasil dari proses } \\
\text { hitung optimasi }\end{array}$ & Diterima \\
\hline \multirow[t]{2}{*}{ Menambah user } & $\begin{array}{l}\text { menginputkan } \\
\text { datauser dengan } \\
\text { benar }\end{array}$ & Diterima \\
\hline & $\begin{array}{l}\text { tidak mengisi } \\
\text { salah satu data }\end{array}$ & Diterima \\
\hline Menghapus user & $\begin{array}{l}\text { penghapusan } \\
\text { data user } \\
\text { berdasarkan id } \\
\text { user }\end{array}$ & Diterima \\
\hline Mengubah user & $\begin{array}{l}\text { Mengubah data } \\
\text { detail dmu } \\
\text { dengan benar }\end{array}$ & Diterima \\
\hline \multirow{2}{*}{$\begin{array}{l}\text { Menambah } \\
\text { fakultas }\end{array}$} & $\begin{array}{l}\text { menginputkan } \\
\text { datafakultas } \\
\text { dengan benar }\end{array}$ & Diterima \\
\hline & $\begin{array}{l}\text { tidak mengisi } \\
\text { salah satu data }\end{array}$ & Diterima \\
\hline $\begin{array}{l}\text { Menghapus } \\
\text { fakultas }\end{array}$ & $\begin{array}{l}\text { penghapusan } \\
\text { data fakultas } \\
\text { berdasarkan id } \\
\text { fakultas }\end{array}$ & Diterima \\
\hline $\begin{array}{l}\text { Mengubah } \\
\text { fakultas }\end{array}$ & $\begin{array}{l}\text { Mengubah data } \\
\text { detail dmu } \\
\text { dengan benar }\end{array}$ & Diterima \\
\hline
\end{tabular}




\section{KESIMPULAN}

Kesimpulan yang dapat diambil adalah:

1. Sistem penilain kinerja jurusan/ program studi di Perguruan Tinggi menggunakan Data Envelopment Analysis (DEA) telah berhasil dibangun

2. Sistem ini dapat menentukan nilai efisiensi (optimasi) jurusan dan merupakan evaluasi untuk menentukan kriteria apa yang perlu dinaikkan atau diturunkan agar kinerja jurusan tersebut dapat optimal. Hasil perhitungan sistem bernilai valid karena hasil yang dikeluarkan sama dengan hasil perhitungan yang dilakukan dengan perhitungan secara manual.

\section{DAFTAR PUSTAKA}

[1] Agha, S.R. et al., 2011. Assesment of Academic Departments Efficiency Using Data Envelopment Analysis. Journal of Industrial Engineering and Managemenet 4(2), pp.301-25.

[2] BAN-PT, 2009. Standar dan Prosedur Akreditasi Program Studi Sarjana. Jakarta: Direktorat Pendidikan Tinggi.

[3] Charnes, A., Cooper, W.W. \& Rhodes, E., 1978. Measuring The Efficiency of Decision Making Units. European Journal of Operasional Research 2 (6), pp.429-44.
[4] Kao, C. \& Hung, H., 2008. Efficiency Analysis of University departments : An Empircal Study. Omega36, pp.653-64.

[5] Kusuma, R., 2014. Metode Dual Simpleks. [Online] Available at: http://rezakusuma.blog.com/metode-dualsimpleks/ [Accessed 7 Agustus 2014].

[6] Pressman, R., 2001. Software Engineering : A Practitioner's Approach. New York: McGraw-Hill.

[7] Rusydiana, A., 2013. DEA Center. [Online] Available at: http://deacenter.blogspot.com/2013/03/kelebihandan-kekurangan-dea_2893.html [Accessed 1 Mei 2014].

[8] Sauter, L.V., 1997. Decision Support Systems for Business Intelligence. St. Louis: University of Missouri.

[9] Sauter, L.V., 1997. Decision Support Systems for Business Intelligence. St. Louis: University of Missouri.

[10] Turban, E., dkk, Decision Support Systems and Intelligent Systems $-7^{\text {th }} E d$, Terjemahan Dwi Prabantini, Yogyakarta : ANDI, 2005.

[11] Zhu, J., 2009. Quantitative Models for Performance Evaluation and Benchmarking. New York: Springer 